\title{
The effect of high concentration of magnesium with ropivacaine, gentamicin, rocuronium, and their combination on neuromuscular blockade
}

\author{
Won Ji Rhee ${ }^{1}$, Seung Yoon Lee ${ }^{2}$, Ji Hyeon Lee ${ }^{2}$, So Ron Choi ${ }^{2}$, \\ Seung-Cheol Lee ${ }^{2}$, Jong Hwan Lee ${ }^{2}$, and Soo-Il Lee ${ }^{2}$ \\ Department of Anesthesiology and Pain Medicine, ${ }^{1}$ Dong-eui Medical Center, ${ }^{2}$ Dong-A University College of \\ Medicine, Busan, Korea
}

\begin{abstract}
Background: Magnesium, ropivacaine, gentamicin, and rocuronium block neuromuscular (NM) transmission by different mechanisms. Therefore, concurrent administration of these agents may induce prolonged muscle paralysis via synergistic interaction. This study investigated the efficacy and safety of NM block caused by the administration of high concentrations of magnesium in combination with ropivacaine, gentamicin, and rocuronium.

Methods: Eighty-three left phrenic nerve-hemidiaphragms from male SD rats (150-250 g) were hung in Krebs solution. Three consecutive single twitch tension (ST, $0.1 \mathrm{~Hz}$ ) and one tetanic tension (TT, $50 \mathrm{~Hz}$ for $1.9 \mathrm{~s}$ ) were obtained before drug application and at each new drug concentration. The concentration of $\mathrm{MgCl}_{2}$ and $\mathrm{MgSO}_{4}$ in Krebs solution was increased until an 80 to $90 \%$ reduction in ST was reached. To test the effects of combinations of NM agents, a Krebs solution was premixed with $\mathrm{MgCl}_{2}$ alone, $\mathrm{MgCl}_{2}$ and ropivacaine, or $\mathrm{MgCl}_{2}$, ropivacaine, and gentamicin. The concentration of ropivacaine, gentamicin, or rocuronium was then progressively increased until an 80 to $90 \%$ reduction in ST was reached. The effective concentrations were estimated with a probit model.

Results: The potency of $\mathrm{MgCl}_{2}$ was greater than that of $\mathrm{MgSO}_{4}$, and pretreatment with $\mathrm{MgCl}_{2}$ increased the potency of gentamicin and rocuronium. Unexpectedly, $\mathrm{MgCl}_{2}$ did not potentiate ropivacaine, and the potency of gentamicin and rocuronium failed to show an increase when premixed with $0.5 \mu \mathrm{M}$ ropivacaine.

Conclusions: The concomitant administration of high concentrations of magnesium and ropivacaine together with clinically relevant concentrations of gentamicin or rocuronium potentiated NM blockade but not with clinically relevant concentrations of ropivacaine. (Korean J Anesthesiol 2015; 68: 50-61)
\end{abstract}

Key Words: Gentamicins, Magnesium, Neuromuscular blockade, Rocuronium, Ropivacaine

Corresponding author: Soo-Il Lee, M.D., Ph.D.

Department of Anesthesiology and Pain Medicine, Dong-A

University College of Medicine, 26, Daesingongwon-ro, Seo-gu, Busan 602-715, Korea

Tel: 82-51-240-5390, Fax: 82-51-247-7819

E-mail: silee@dau.ac.kr

Received: June 24, 2014.

Revised: 1st, August 6, 2014; 2nd, September 17, 2014.

Accepted: September 19, 2014.

Korean J Anesthesiol 2015 February 68(1): 50-61 http://dx.doi.org/10.4097/kjae.2015.68.1.50

\section{Introduction}

Magnesium is the fourth most common mineral in the body and it plays a central role in the regulation of cellular function, and also acts as a natural calcium antagonist [1,2]. Mechanistically, it competes with calcium in synaptic junctions [3] and influences calcium-dependent neurotransmitter release [4]. Physiologically, it antagonizes calcium-dependent arterial constriction, and high doses of magnesium have been widely used for the control and prevention of eclamptic convulsions [3].

(c) This is an open-access article distributed under the terms of the Creative Commons Attribution Non-Commercial License (http://creativecommons.org/ licenses/by-nc/3.0/), which permits unrestricted non-commercial use, distribution, and reproduction in any medium, provided the original work is properly cited. 
Besides the beneficial effect in eclampsia, the therapeutic use of magnesium has been gradually growing as an adjuvant in general anesthesia, regional anesthesia, and pain control [1].

Although magnesium, as outlined above, has many beneficial pharmacologic properties, it also causes dose-dependent side effects. The most serious side effect is neuromuscular (NM) block. NM block may result in hypoxemia and re-intubation that cause pneumonia, brain damage, and even death. Magnesium paralyzes skeletal muscle dose-dependently by competing with calcium on the presynaptic membrane and inhibiting calciumdependent acetylcholine release [4]. Therefore, it can prolong the action of nondepolarizing neuromuscular blocking agents (NMBAs) [5] and can aggravate muscle weakness in vulnerable patients with Lambert-Eaton syndrome or myasthenia gravis [1]. Finally, the NM blockade by magnesium can be aggravated by co-administration with other drugs such as local anesthetics, analgesics and anesthetics, muscle relaxants, and antibiotics, which is common during the perioperative period.

One such medication administered with magnesium during the perioperative period is ropivacaine. Ropivacaine is an amino amide local anesthetic with structural similarity to bupivacaine $[6,7]$. Because of its reduced central nervous system exposure and cardiac toxicity, it is a commonly used local anesthetic [6]. Like other local anesthetics including bupivacaine, it may act on motor nerve terminals and motor nerve conduction and thereby cause interference with NM transmission and potentiate NMBAs [8-10]. However, some studies report an interaction between ropivacaine and other drugs on NM blockade.

Gentamicin is a widely used aminoglycoside antibiotic that is provided to patients by anesthesiologists [11]. Like magnesium, it enhances NM block by opposing synaptic calcium influx and consequently decreases acetylcholine release at the nerve-muscle junction $[11,12]$. However, although gentamicin is concomitantly administered with other drugs, the interaction with those other drugs on NM blockade has been rarely reported.

Magnesium, ropivacaine, gentamicin, and rocuronium have different mechanisms of NM block. They may act synergistically to enhance NM inhibition, which consequently reduces their effective concentrations to achieve the same degree of NM block. In addition, perioperatively, it is not uncommon to find patients with hypermagnesemia. Thus, the aim of this study is to evaluate the degree of NM block caused by high concentrations of magnesium combined with ropivacaine, gentamicin, and rocuronium.

\section{Materials and Methods}

The Institutional Animal Care and Use Committee approved the experimental protocol. All experimental courses followed the Guide for the Care and Use of Laboratory Animals provided by the National Academy of Sciences. Eighty-three male SpragueDawley rats (5-7 weeks in age, and 150-250 g in weight) were anesthetized by an intra-abdominal injection of thiopental (250 $\mathrm{mg} / \mathrm{kg}$ ), and then sacrificed. The phrenic nerve and diaphragm was excised en block, and the left diaphragm with the middle diaphragmatic ligament was separated from the rest of the diaphragm. The left phrenic nerve-hemidiaphragm preparations were mounted in a $20 \mathrm{ml}$ organ bath filled with oxygenated (95\% $\mathrm{O}_{2}, 5 \% \mathrm{CO}_{2}$ ) Krebs solution (118 mM NaCl, $5 \mathrm{mM} \mathrm{KCl}, 2.5 \mathrm{mM}$ $\mathrm{CaCl}_{2}, 30 \mathrm{mM} \mathrm{NaHCO}, 1 \mathrm{mM} \mathrm{KH} \mathrm{PO}_{4}, 1 \mathrm{mM} \mathrm{MgCl}_{2}$ and 11 $\mathrm{mM}$ glucose).

The bath solution was maintained at $32^{\circ} \mathrm{C}$ and continuously aerated with a gas mixture of $95 \%$ oxygen and $5 \%$ carbon dioxide. The $\mathrm{pH}$ of the bath solution was maintained at 7.38 to 7.42 . Spent Krebs solution was exchanged with fresh solution $10 \mathrm{~min}$ after the preparation was mounted. The preparation was attached to a force transducer (Model 1030, UFI, Morro Bay, CA, USA) with a stainless steel wire and allowed to stabilize for 20 min in the bath. The phrenic nerve, connected to an electrode, was stimulated with supramaximal square wave impulses of 0.2 ms in duration using a stimulator (Model ML112, AD Instruments Pty Ltd, Bella Vista, NSW, Australia).

The preparation was stretched until the maximum output tension was recorded, and then followed by another $10 \mathrm{~min}$ for stabilization before each experiment began. At every drug concentration, a period of $20 \mathrm{~min}$ was allowed to elapse to establish a pseudosteady state between the solution and muscle tissue before tension measurements were made. Before drug application for a baseline and at each new drug concentration, three consecutive single twitches (ST) at $0.1 \mathrm{~Hz}$ and a 1.9-s tetanic tension (TT) of $50 \mathrm{~Hz}$ were recorded, and then digitized and stored on a Power Macintosh 7100 (Apple Computer Corp, Cupertino, CA, USA) using data acquisition software (MacLab, ADInstruments Pty Ltd, Bella Vista, NSW, Australia).

After the baseline tensions were measured, to compare the potencies of $\mathrm{MgCl}_{2}$ and $\mathrm{MgSO}_{4}$, the concentrations of $\mathrm{MgCl}_{2}$ (n =4) and $\mathrm{MgSO}_{4}(\mathrm{n}=3)$ in the Krebs solutions were cumulatively increased by the way of $3,5,7,9,10,10.5,11.5,13 \mathrm{mM}$ and 7.5 , $12.5,17.5,22.5,27.5,32.5 \mathrm{mM}$, respectively, until an $80-90 \%$ reduction in ST reached.

In order to determine whether magnesium would enhance ropivacaine-induced NM blockade, a Krebs solution was premixed with $1(\mathrm{Mg} 1, \mathrm{n}=4), 2(\mathrm{Mg} 2, \mathrm{n}=3)$, or $4(\mathrm{Mg} 4, \mathrm{n}=4)$ $\mathrm{mM} \mathrm{MgCl}$, and then the concentration of ropivacaine was cumulatively increased by the way of $0.1,1,10,30,50,70,90,120$, $150 \mathrm{mM}$ until an $80-90 \%$ reduction in ST reached.

To assess the effects of magnesium alone or the combination of magnesium and ropivacaine on gentamicin-induced muscle relaxation, a Krebs solution was pretreated as follows: for concentration sets of $\mathrm{MgCl}_{2}$ alone, $1(\mathrm{Mg} 1, \mathrm{n}=4) ; 2(\mathrm{Mg} 2, \mathrm{n}=4) ; 4$ 
$(\mathrm{Mg} 4, \mathrm{n}=3) \mathrm{mM}$; for concentration sets of $\mathrm{MgCl}_{2}$ and ropivacaine, 2 and $0.5(\mathrm{Mg} 2 \mathrm{Rv} 0.5, \mathrm{n}=4) ; 2 \mathrm{mM}$ and $1 \mu \mathrm{M}$ (Mg2Rv1, $\mathrm{n}=4$ ). Then, the concentration of gentamicin was cumulatively increased by the way of adding from 0.1 to $2.1 \mathrm{mM}$ until an 80-90\% reduction in ST reached.

To analyze whether magnesium alone, the combination of magnesium and ropivacaine, or the combination of magnesium, ropivacaine and gentamicin potentiates the rocuroniuminduced NM block, a Krebs solution was premixed as follows: for concentration sets of $\mathrm{MgCl}_{2}$ alone, $1(\mathrm{Mgl}, \mathrm{n}=4) ; 1.5(\mathrm{Mg} 1.5$, $\mathrm{n}=4) ; 2(\mathrm{Mg} 2, \mathrm{n}=5) \mathrm{mM}$; for concentration sets of $\mathrm{MgCl}_{2}$ and ropivacaine, 1.5 and $0.5(\mathrm{Mg} 1.5 \mathrm{Rv} 0.5, \mathrm{n}=5) ; 2 \mathrm{mM}$ and $0.5 \mu \mathrm{M}$ ( $\mathrm{Mg} 2 \mathrm{Rv} 0.5, \mathrm{n}=8$ ); for concentration sets of $\mathrm{MgCl}_{2}$, ropivacaine, and gentamicin, 1.5, 0.5, and $20(\mathrm{Mg} 1.5 \mathrm{Rv} 0.5 \mathrm{Gm} 20, \mathrm{n}=5) ; 2$ $\mathrm{mM}, 0.5 \mu \mathrm{M}$, and $20 \mu \mathrm{M}(\mathrm{Mg} 2 \mathrm{Rv} 0.5 \mathrm{Gm} 20, \mathrm{n}=7)$. Then, the concentration of rocuronium was cumulatively increased by the way of $1,3,5,7,9,12,14,16,18,20,22,24 \mu \mathrm{M}$ until an $80-90 \%$ reduction in ST reached. The schematic design of the experiment is shown Fig. 1.

After data were acquired, the bath chamber that drugs tested were washed out with fresh Krebs solution. Then, an ST tension was recorded in a drug-free solution. Data from a preparation were analyzed only if the ST tension of the preparation returned to a value greater than $90 \%$ of the baseline.

Mean ST tension was got by averaging three consecutive measurements. Peak tetanic tension (PTT) and end tetanic tension
(ETT) were measured at $0.2 \mathrm{~s}$ and $1.9 \mathrm{~s}$ after the start of tetanic stimulation, respectively. The effect of drug on ST, PTT, and ETT was presented as a percent reduction of the baseline. The effective concentrations (ECs) of the four drugs were estimated by nonparametrically on a probit model. The concentration-response (C-R) curves for ST, PTT, and ETT were plotted.

Data were presented as mean \pm standard error mean (SEM). The percent inhibition of ST, PTT, ETT of ropivacaine, gentamicin, or rocuronium in a certain concenration and the half maximal effective concentration $\left(\mathrm{EC}_{50}\right)$ of the drugs were compared between pre-treatment groups using a Student's t-test with Bonferroni's correction for the significance level. Differences were considered significant when $\mathrm{P}<0.05$.

\section{Results}

Before examining the interaction of magnesium with other drugs, we first established the baseline $\mathrm{EC}_{50}$ for $\mathrm{MgCl}_{2}$ and $\mathrm{MgSO}_{4}$ on NM block. The $\mathrm{EC}_{50}$ of $\mathrm{MgCl}_{2}$ for ST, PTT, and ETT were $9.52 \pm 0.09,9.91 \pm 0.08$, and $9.60 \pm 0.08 \mathrm{mM}$, respectively. The $\mathrm{EC}_{50}$ of $\mathrm{MgSO}_{4}$ for ST, PTT, and ETT were $22.07 \pm 1.17$, $24.17 \pm 1.22$, and $23.70 \pm 1.38 \mathrm{mM}$, respectively. Although the $\mathrm{EC}_{50}$ of both magnesium compounds were over therapeutic doses, the potency of $\mathrm{MgCl}_{2}$ on NM inhibition was significantly greater than that of $\mathrm{MgSO}_{4}$. The potencies of both agents for ST, PTT, and ETT were similar in concentration (Fig. 2).

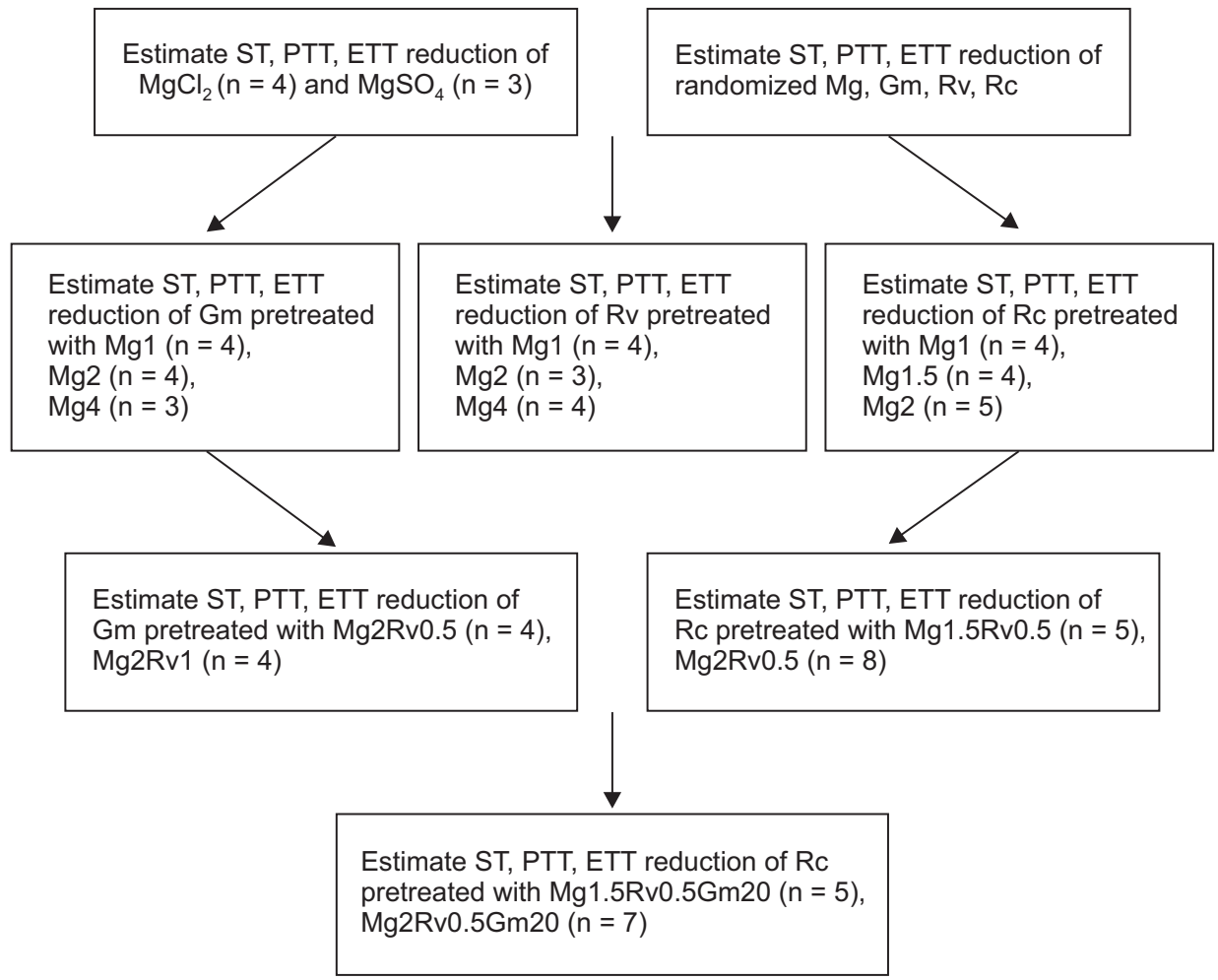

Fig. 1. The experimental design. The units of concentrations for $\mathrm{Mg}, \mathrm{Rv}$, and $\mathrm{Gm}$ are $\mathrm{mM}, \mu \mathrm{M}, \mu \mathrm{M}$, respectively. $\mathrm{n}$ is the number of experiments. Mg: magnesium chloride, Gm: gentamicin, Rv: ropivacaine, Rc: rocuronium, ST: single twitch, PTT: peak tetanic tension, ETT: end tetanic tension. 
A

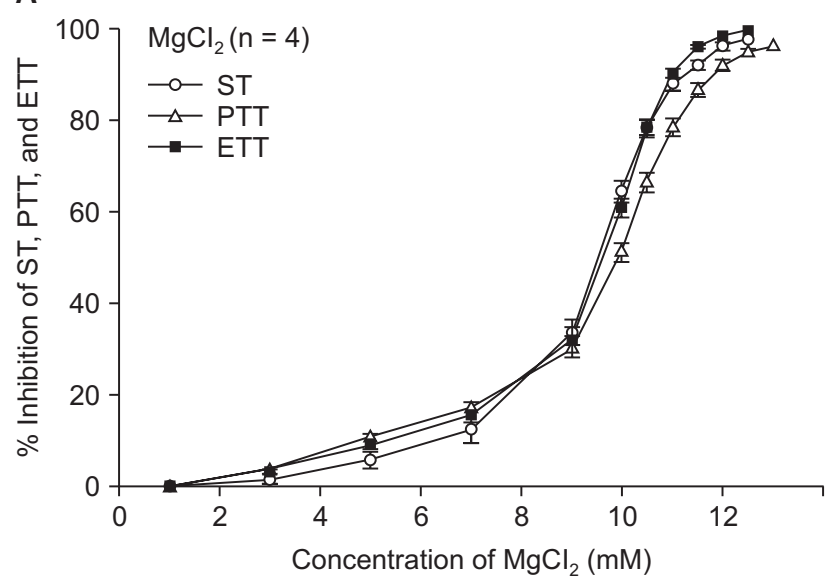

B

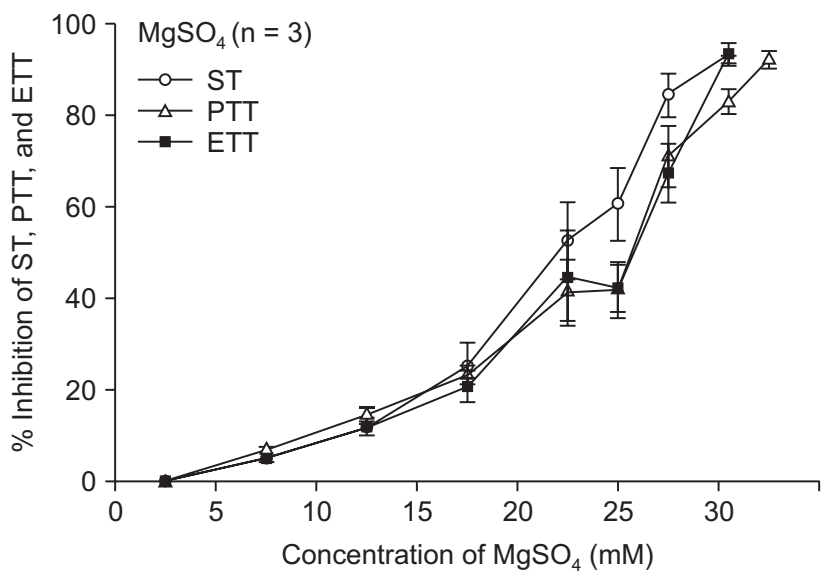

Fig. 2. The cumulative concentration-response (C-R) curves of $\mathrm{MgCl}_{2}(\mathrm{~A})$ and $\mathrm{MgSO}_{4}$ (B) on the single twitch (ST) at $0.1 \mathrm{~Hz}$ and peak tetanic tension (PTT) and end tetanic tension (ETT) at $50 \mathrm{~Hz}$ for 1.9 seconds. The decline trends of ST, PTT, and ETT are similar to each other. PTT remains after disappearance of ST and ETT at the highest concentrations of two chemicals. Data are presented as mean \pm SEM. $n$ is the number of experiments.

A

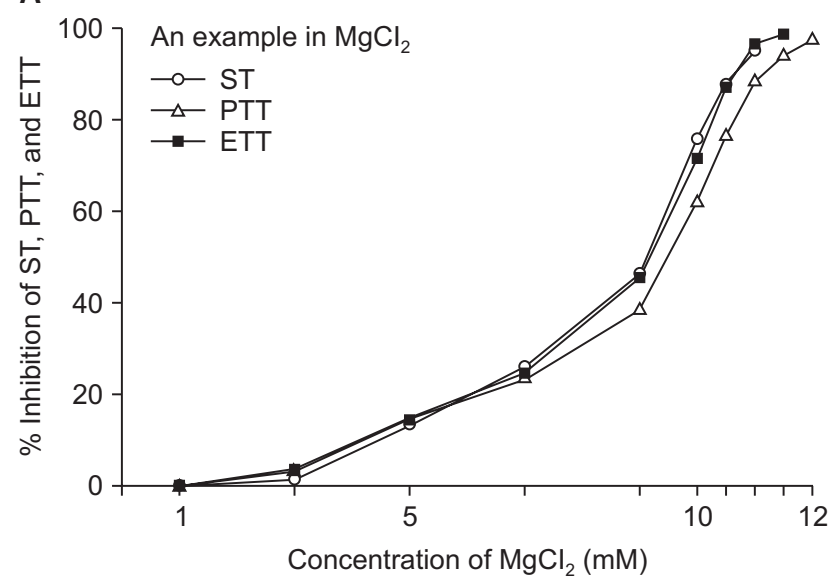

C

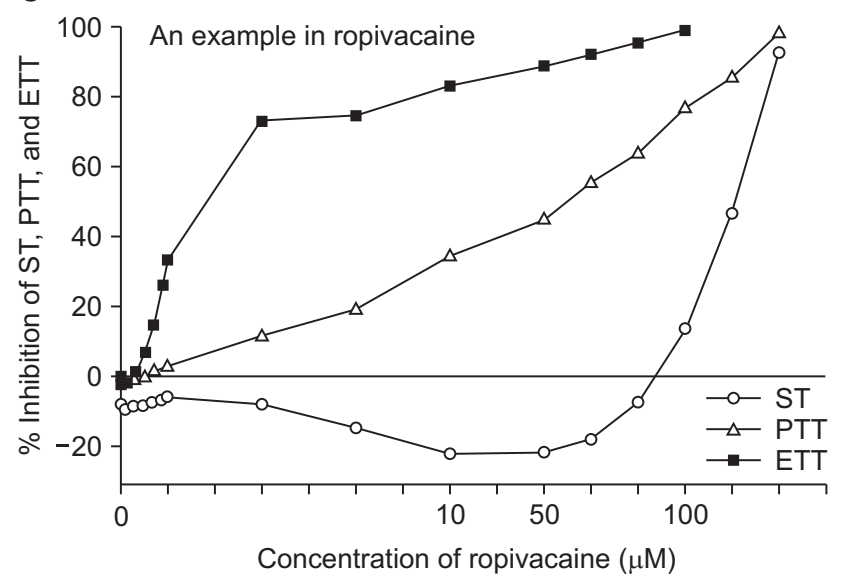

B

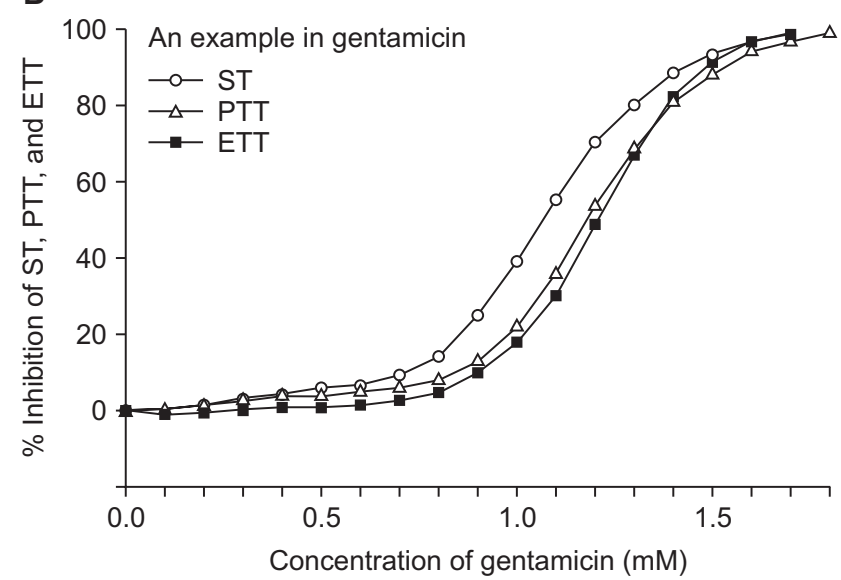

D

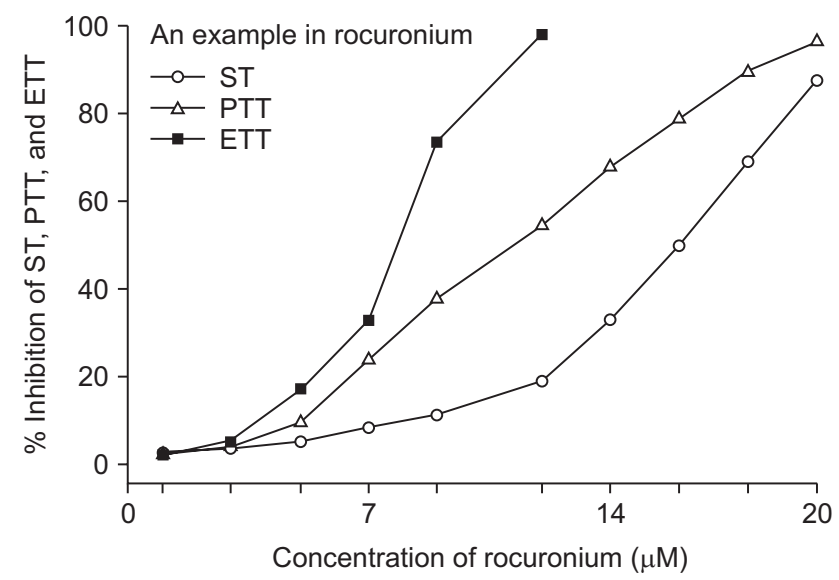

Fig. 3. Magnesium chloride (A), gentamicin (B), ropivacaine (C), and rocuronium (D) each reduces ST, PTT, and ETT. Based on the cumulative concentration-response $(\mathrm{C}-\mathrm{R})$ curves of $\mathrm{MgCl}_{2}$ and gentamicin, PTT and ETT are still alive after ST vanishes at the higher concentration. On the contrast, based on the C-R curves of ropivacaine and rocuronium on ST, PTT, and ETT, tetanic tension reduction appears at concentrations lower than ST inhibition appears. ST and PTT sustain until the highest concentration of two agents after ETT vanishes. Ropivacaine enhances ST, PTT, and ETT at the concentration less than 110, 5, $1 \mu \mathrm{M}$, respectively. ST: single twitch, PTT: peak tetanic tension, ETT: end tetanic tension. 
Magnesium chloride, ropivacaine, gentamicin, and rocuronium each reduced ST, PTT, and ETT (Fig. 3). Magnesium chloride and gentamicin induced a similar degree of reduction in ST, PTT, and ETT, but PTT and ETT persisted after ST disappeared at the higher concentration of the two drugs (Figs. 3A and B). In contrast, reduction of tetanic tension induced by ropivacaine and rocuronium appeared at lower concentrations than ST inhibition appeared (Figs. 3C and D). Moreover, ropivacaine revealed its dual effect on ST, PTT, and ETT at concentrations less than 110,5 , and $1 \mu \mathrm{M}$, respectively (Fig. $3 \mathrm{C}$ ).

There was no significant difference in the $\mathrm{EC}_{50}$ of ropivacaine between pretreated groups (Table 1 ). $\mathrm{MgCl}_{2}$ shifted the $\mathrm{C}-\mathrm{R}$ curves of ropivacaine to the left (Fig. 4), but despite increased concentration of magnesium, it did not significantly increase the potency of ropivacaine. In addition, ropivacaine pretreatment with $1 \mathrm{mM} \mathrm{MgCl}_{2}$ caused greater ST over baseline at two concentration phases, a lower concentration level from 0.1 to 5 $\mu \mathrm{M}$ and a higher concentration level from 50 to $90 \mu \mathrm{M}$ (Fig. 4). It also started to inhibit PTT and ETT at concentrations lower than the concentrations at which ST inhibition appeared (Fig. 4).

The comparison of $\mathrm{EC}_{50}$ of gentamicin between pretreatment groups is presented in Table 2. Despite the increase in $\mathrm{MgCl}_{2}$ concentration, there were no differences in $\mathrm{EC}_{50}$ between gentamicin in $1 \mathrm{mM} \mathrm{MgCl}_{2}$ and gentamicin in $2 \mathrm{mM} \mathrm{MgCl}_{2}$ and 0.5 $\mu \mathrm{M}$ ropivacaine. $\mathrm{MgCl}_{2}$ alone shifted the $\mathrm{C}-\mathrm{R}$ curves of gentamicin for ST, PTT, and ETT to the left (Fig. 5). Unexpectedly, 0.5

Table 1. Comparison of EC50 Values of Ropivacaine between Pre-treat Groups

\begin{tabular}{|c|c|c|c|}
\hline Pre-treat group & $\mathrm{EC}_{50}$ of ST $(\mu \mathrm{M})$ & $\mathrm{EC}_{50}$ of PTT $(\mu \mathrm{M})$ & $\mathrm{EC}_{50}$ of ETT $(\mu \mathrm{M})$ \\
\hline $\operatorname{Mg} 1 \mathrm{mM}(\mathrm{n}=4)$ & $112.70 \pm 5.86$ & $71.22 \pm 6.52$ & $11.21 \pm 0.73$ \\
\hline $\operatorname{Mg} 2 \mathrm{mM}(\mathrm{n}=3)$ & $98.41 \pm 2.08$ & $56.17 \pm 5.68$ & $9.89 \pm 0.37$ \\
\hline $\mathrm{Mg} 4 \mathrm{mM}(\mathrm{n}=4)$ & $74.72 \pm 2.55$ & $37.91 \pm 2.92$ & $7.58 \pm 0.26$ \\
\hline
\end{tabular}

Data are mean \pm SEM. No significant differences between the groups were noted. $\mathrm{EC}_{50}$ : effective concentration of $50 \%$ maximal effect, $\mathrm{Mg}_{\mathrm{MgCl}}$, $\mathrm{ST}$ : single twitch, PTT: peak tetanic tension, ETT: end tetanic tension.

A

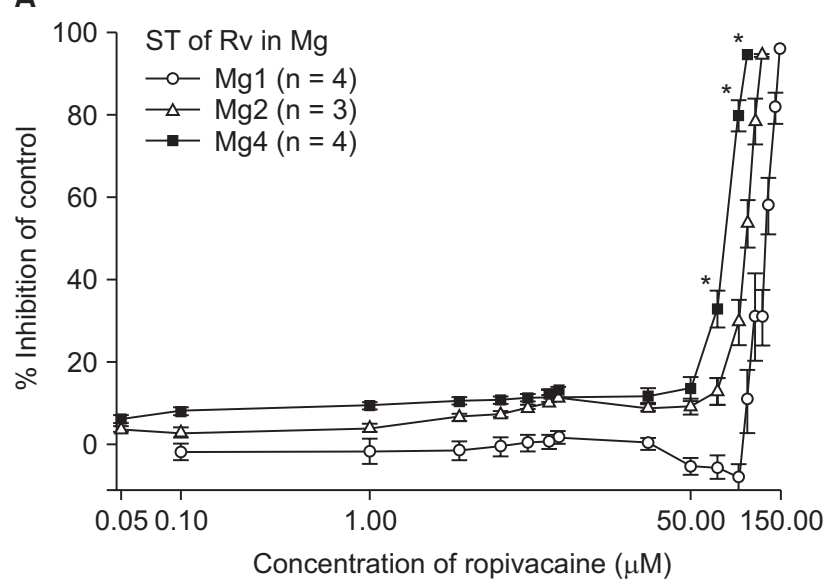

C

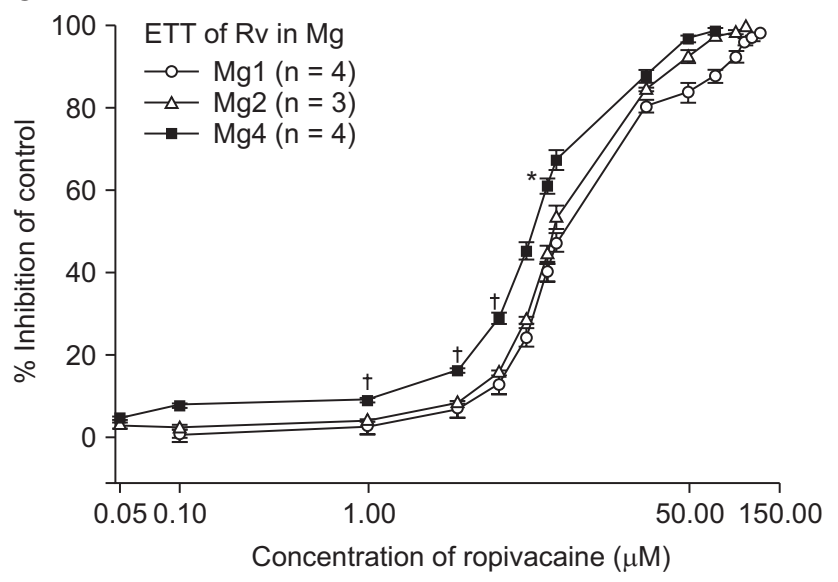

B

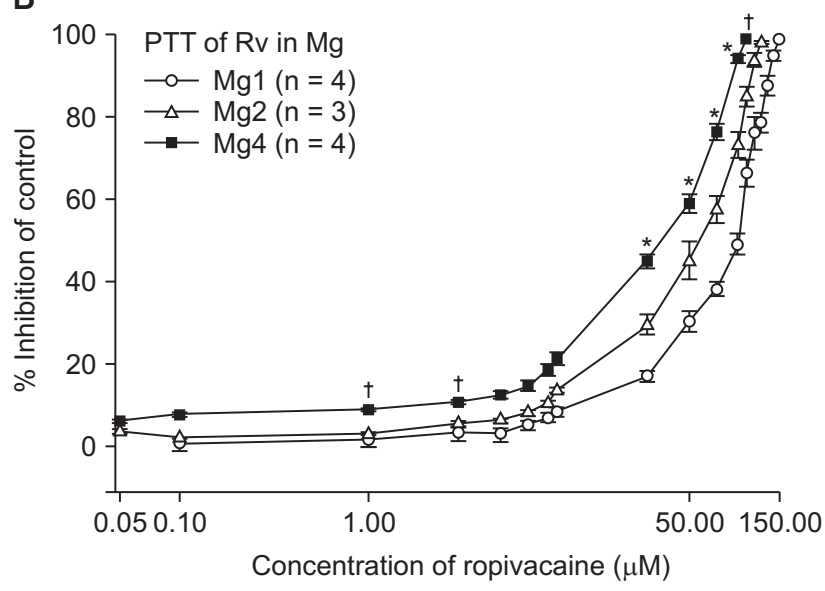

Fig. 4. Based on the cumulative concentration-response (C-R) curves of ropivacaine on ST (A), PTT (B) and ETT (C), $\mathrm{MgCl}_{2}$ shifts the C-R curves of ropivacaine to the left. In addition, ropivacaine pretreated with $1 \mathrm{mM} \mathrm{MgCl}_{2}$ reveals dual effect at the lower and higher concentration. The concentration of ropivacaine is transformed to log concentration. Data are presented as mean \pm SEM. The unit of concentrations for $\mathrm{Mg}$ is $\mathrm{mM} . \mathrm{n}$ is the number of experiments. Mg: magnesium chloride, Rv: ropivacaine, ST: single twitch, PTT: peak tetanic tension, ETT: end tetanic tension. ${ }^{*} \mathrm{P}<0.05$, vs. $\mathrm{Mg} 1 \mathrm{mM}$, and ${ }^{\dagger} \mathrm{P}<0.05$, vs. $\mathrm{Mg} 2 \mathrm{mM}$ by t-test with Bonferroni's correction. 
$\mu \mathrm{M}$ ropivacaine shifted the $\mathrm{C}-\mathrm{R}$ curves of gentamicin in $2 \mathrm{mM}$ magnesium to the right, and, thus, reversed the potency of gentamicin (Fig. 6).

The $\mathrm{EC}_{50}$ comparison of rocuronium between pretreated groups is shown in Table 3. As the concentration of pretreated $\mathrm{MgCl}_{2}$ increased, the $\mathrm{EC}_{50}$ of ST, PTT, and ETT decreased. However, the addition of $0.5 \mu \mathrm{M}$ ropivacaine to the pretreament decreased the $\mathrm{EC}_{50}$ of rocuronium. $\mathrm{MgCl}_{2}$ alone shifted the $\mathrm{C}-\mathrm{R}$ curves of rocuronium for ST, PTT, and ETT to the left (Fig. 7). Unexpectedly, ropivacaine $(0.5 \mu \mathrm{M})$ added to rocuronium in 1.5
$\mathrm{mM}$ or $2 \mathrm{mM} \mathrm{MgCl}_{2}$ shifted the C-R curves of rocuronium to the right (Figs. 8 and 9). However, the addition of $20 \mu \mathrm{M}$ gentamicin to rocuronium in $1.5 \mathrm{mM} \mathrm{MgCl}_{2}$ and $0.5 \mu \mathrm{M}$ ropivacaine or $2 \mathrm{mM} \mathrm{MgCl}_{2}$ and $0.5 \mu \mathrm{M}$ ropivacaine moved the C- $\mathrm{R}$ curves to the left; hence, it reversed the antagonistic action of ropivacaine (Figs. 8 and 9). Rocuronium pretreatment with $1.5 \mathrm{mM}$ $\mathrm{MgCl}_{2}$ and $0.5 \mu \mathrm{M}$ ropivacaine revealed ST, PTT, and ETT equal to or greater than baseline tensions at concentrations less than 9,5 , and $3 \mu \mathrm{M}$, respectively (Fig. 8). The combination of $1.5 \mathrm{mM}$ $\mathrm{MgCl}_{2}, 0.5 \mu \mathrm{M}$ ropivacaine, and $20 \mu \mathrm{M}$ gentamicin also showed

Table 2. Comparison of EC50 Values of Gentamicin between Pre-treat Groups

\begin{tabular}{|c|c|c|c|}
\hline Pre-treat group & $\mathrm{EC}_{50}$ of $\mathrm{ST}(\mathrm{mM})$ & $\mathrm{EC}_{50}$ of PTT $(\mathrm{mM})$ & $\mathrm{EC}_{50}$ of ETT $(\mathrm{mM})$ \\
\hline $\operatorname{Mg} 1 \mathrm{mM}(\mathrm{n}=4)$ & $1.38 \pm 0.02 *$ & $1.51 \pm 0.02 *$ & $1.54 \pm 0.02 *$ \\
\hline $\operatorname{Mg} 2 \mathrm{mM}(\mathrm{n}=4)$ & $0.97 \pm 0.04$ & $1.08 \pm 0.03$ & $1.09 \pm 0.04$ \\
\hline $\mathrm{Mg} 4 \mathrm{mM}(\mathrm{n}=3)$ & $0.85 \pm 0.03^{\dagger}$ & $1.00 \pm 0.03^{\dagger}$ & $0.99 \pm 0.02^{\dagger}$ \\
\hline $\mathrm{Mg} 2 \mathrm{mM}+\operatorname{Rv} 0.5 \mu \mathrm{M}(\mathrm{n}=4)$ & $1.24 \pm 0.02^{\ddagger}$ & $1.32 \pm 0.02$ & $1.30 \pm 0.02^{\ddagger}$ \\
\hline $\mathrm{Mg} 2 \mathrm{mM}+\operatorname{Rv} 1 \mu \mathrm{M}(\mathrm{n}=4)$ & $0.98 \pm 0.02$ & $1.10 \pm 0.01$ & $1.05 \pm 0.01$ \\
\hline
\end{tabular}

Data are mean $\pm \mathrm{SEM}_{\text {. }} \mathrm{EC}_{50}$ : effective concentration of $50 \%$ maximal effect, $\mathrm{Mg}: \mathrm{MgCl}_{2}$, Rv: ropivacaine, ST: single twitch, PTT: peak tetanic tension, ETT: end tetanic tension. ${ }^{*} \mathrm{P}<0.05$, vs. $\mathrm{Mg} 2 \mathrm{mM}, \mathrm{Mg} 4 \mathrm{mM}$, and $\mathrm{Mg} 2 \mathrm{mM}+\mathrm{Rv} 1 \mu \mathrm{M},{ }^{\dagger} \mathrm{P}<0.05$, vs. $\mathrm{Mg} 2 \mathrm{mM}+\mathrm{Rv} 0.5 \mu \mathrm{M}$, and ${ }^{\dagger} \mathrm{P}<0.05$, vs. $\mathrm{Mg} 2$ $\mathrm{mM}+\mathrm{Rv} 1 \mu \mathrm{M}$ by t-test with Bonferroni's correction.

A

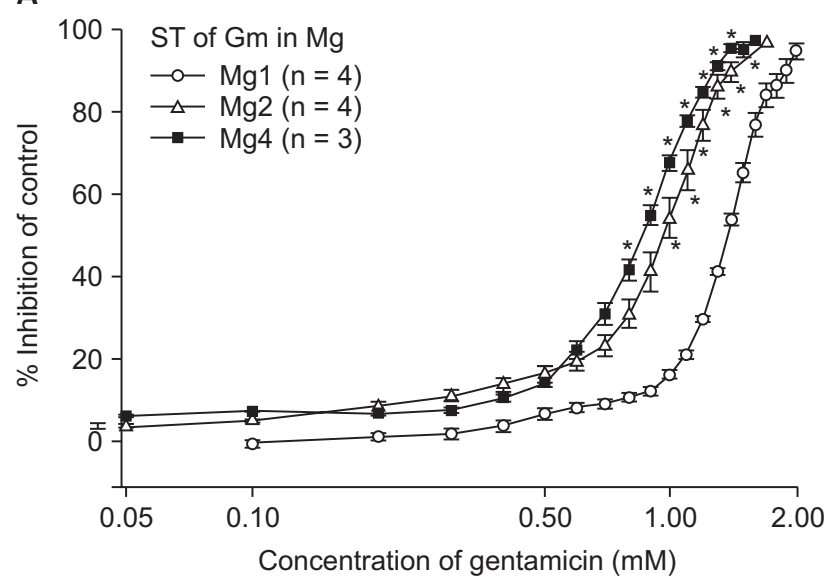

C

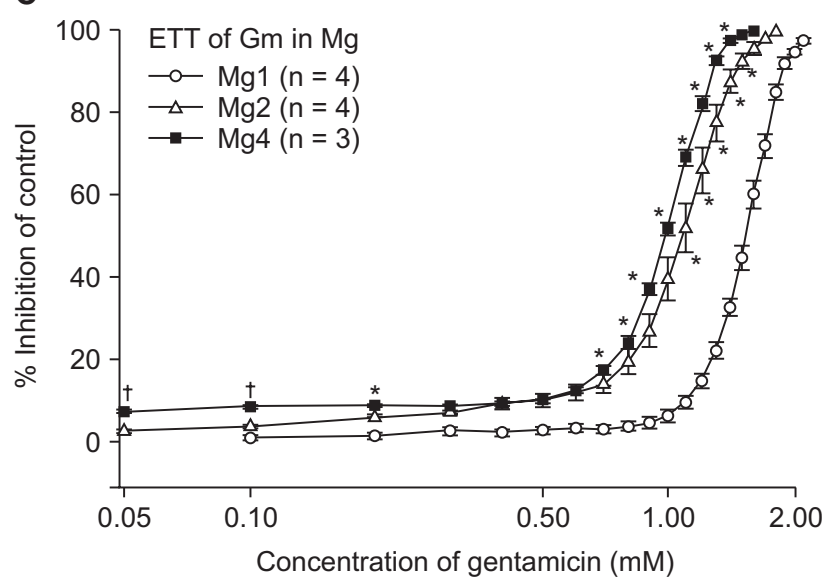

B

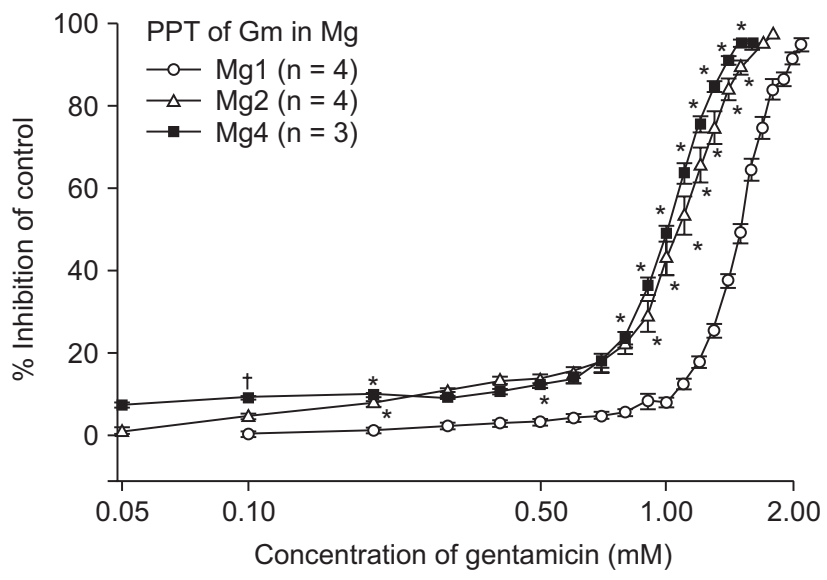

Fig. 5. Based on the cumulative-response $(C-R)$ curves of gentamicin on ST (A), PTT (B) and ETT (C), $\mathrm{MgCl}_{2}$ shifts curves to the left; hence, it augments the potency of gentamicin. The concentration of gentamicin is transformed to log concentration. Data are presented as mean \pm SEM. The unit of concentrations for Mg is $\mathrm{mM}$. $\mathrm{n}$ is the number of experiments. Gm: gentamicin, Mg: magnesium chloride, ST: single twitch, PTT: peak tetanic tension, ETT: end tetanic tension. $* \mathrm{P}<0.05$, vs. $\mathrm{Mg} 1 \mathrm{mM}$, and ${ }^{\dagger} \mathrm{P}<0.05$, vs. $\mathrm{Mg} 2 \mathrm{mM}$ by t-test with Bonferroni's correction. 
A

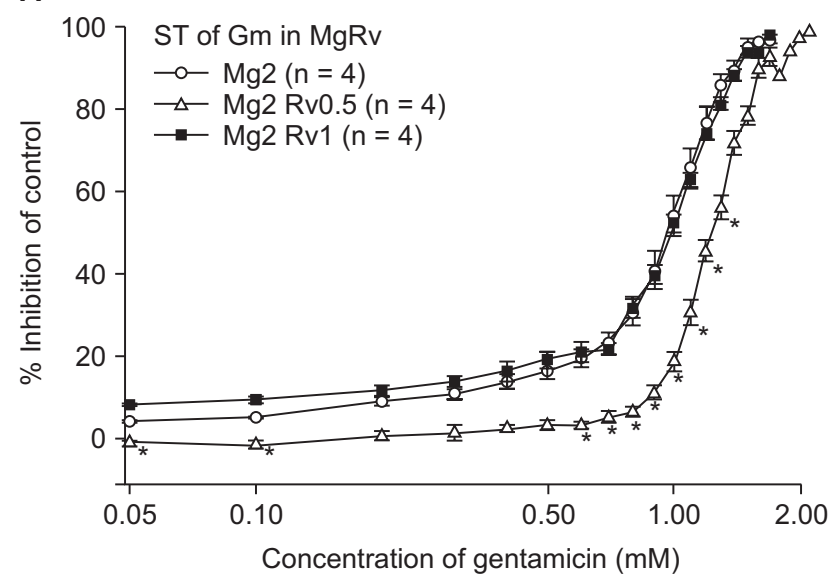

C

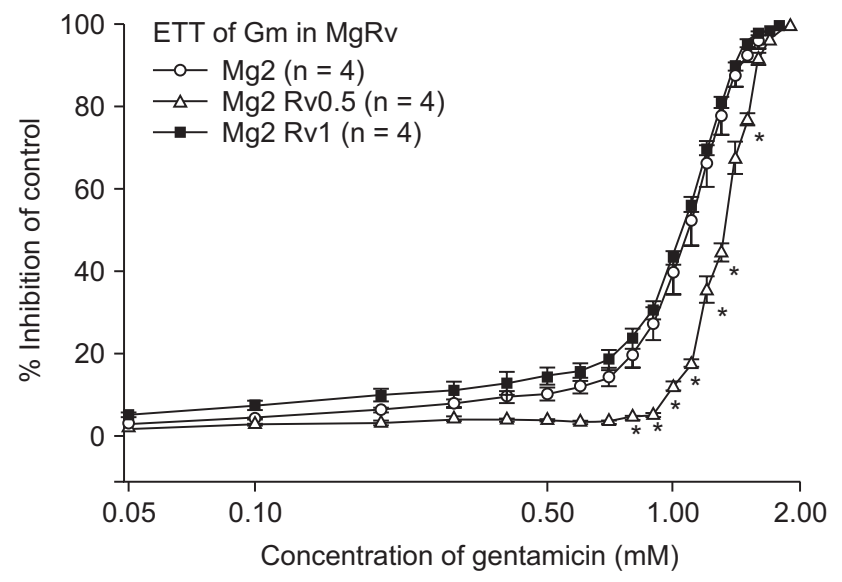

B

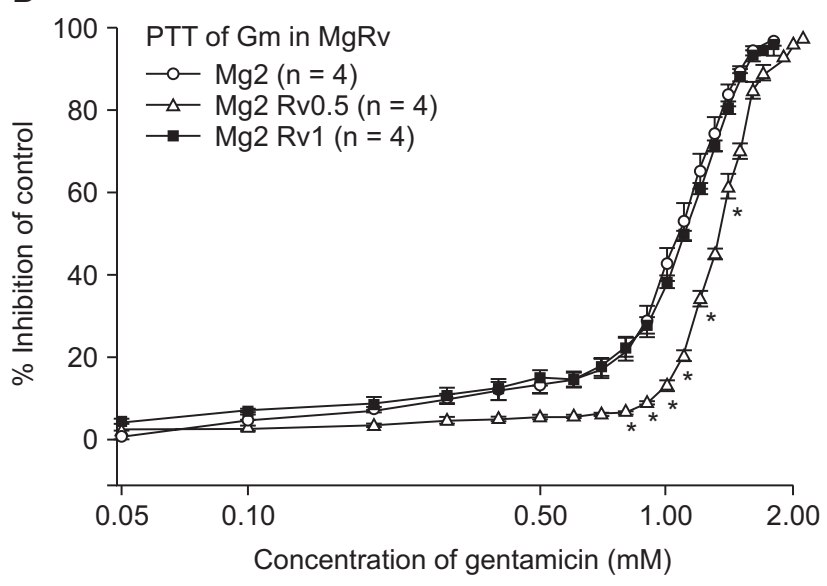

Fig. 6. Based on the cumulative concentration-response (C-R) curves of gentamicin on ST (A), PTT (B) and ETT (C), the combination of 2 $\mathrm{mM} \mathrm{MgCl} 2$ and $0.5 \mu \mathrm{M}$ ropivacaine shifts to the right the C-R curves of gentamicin, and in other words, antagonizes the effect of gentamicin. The concentration of gentamicin is transformed to log concentration. Data are presented as mean \pm SEM. The units of concentrations for $\mathrm{Mg}$ and $\mathrm{Rv}$ are $\mathrm{mM}$ and $\mu \mathrm{M}$, respectively. $\mathrm{n}$ is the number of experiments. $\mathrm{Gm}$ : gentamicin, Mg: magnesium chloride, Rv: ropivacaine, ST: single twitch, PTT: peak tetanic tension, ETT: end tetanic tension. ${ }^{*} \mathrm{P}<0.05$, vs. $\mathrm{Mg} 2 \mathrm{mM}+\mathrm{Rv} 1 \mu \mathrm{M}$ by t-test with Bonferroni's correction.

Table 3. Comparison of EC50 Values of Rocuronium between Pre-treat Groups

\begin{tabular}{|c|c|c|c|}
\hline Pre-treat group & $\mathrm{EC}_{50}$ of $\mathrm{ST}(\mu \mathrm{M})$ & $\mathrm{EC}_{50}$ of PTT $(\mu \mathrm{M})$ & $\mathrm{EC}_{50}$ of $\operatorname{ETT}(\mu \mathrm{M})$ \\
\hline $\mathrm{Mg} 1 \mathrm{mM}(\mathrm{n}=4)$ & $16.72 \pm 0.24^{*}$ & $10.87 \pm 0.16^{\dagger}$ & $7.35 \pm 0.07^{\ddagger}$ \\
\hline $\operatorname{Mg} 1.5 \mathrm{mM}(\mathrm{n}=4)$ & $12.37 \pm 0.46^{\S}$ & $8.44 \pm 0.21^{\S}$ & $5.44 \pm 0.06$ \\
\hline $\operatorname{Mg} 2 \mathrm{mM}(\mathrm{n}=5)$ & $8.33 \pm 0.35^{\|}$ & $6.04 \pm 0.25^{\|}$ & $4.29 \pm 0.28$ \\
\hline $\mathrm{Mg} 1.5 \mathrm{mM}+\operatorname{Rv} 0.5 \mu \mathrm{M}(\mathrm{n}=5)$ & $14.60 \pm 0.21$ & $10.02 \pm 0.26^{n}$ & $6.16 \pm 0.11^{\S}$ \\
\hline $\mathrm{Mg} 2 \mathrm{mM}+\mathrm{Rv} 0.5 \mu \mathrm{M}(\mathrm{n}=8)$ & $9.70 \pm 0.16$ & $7.03 \pm 0.11$ & $4.84 \pm 0.10$ \\
\hline $\mathrm{Mg} 1.5 \mathrm{mM}+\mathrm{Rv} 0.5 \mu \mathrm{M}+\mathrm{Gm} 20 \mu \mathrm{M}(\mathrm{n}=5)$ & $12.14 \pm 0.90^{\S}$ & $7.59 \pm 1.37$ & $5.84 \pm 0.94$ \\
\hline $\mathrm{Mg} 2 \mathrm{mM}+\mathrm{Rv} 0.5 \mu \mathrm{M}+\mathrm{Gm} 20 \mu \mathrm{M}(\mathrm{n}=7)$ & $8.61 \pm 0.80$ & $6.45 \pm 0.49$ & $4.56 \pm 0.44$ \\
\hline
\end{tabular}

Data are mean \pm SEM. $\mathrm{EC}_{50}$ : effective concentration of $50 \%$ maximal effect, $\mathrm{Gm}$ : gentamicin, $\mathrm{Mg}_{\mathrm{MgCl}}$, Rv: ropivacaine, ST: single twitch, PTT: peak tetanic tension, ETT: end tetanic tension. ${ }^{*} \mathrm{P}<0.05$, vs. $\mathrm{Mg} 2 \mathrm{mM}, \mathrm{Mg} 2 \mathrm{mM}+\mathrm{Rv} 0.5 \mu \mathrm{M}, \mathrm{Mg} 1.5 \mathrm{mM}+\mathrm{Rv} 0.5 \mu \mathrm{M}+\mathrm{Gm} 20 \mu \mathrm{M}$, and Mg $2 \mathrm{mM}+\mathrm{Rv}$ $0.5 \mu \mathrm{M}+\mathrm{Gm} 20 \mu \mathrm{M},{ }^{\dagger} \mathrm{P}<0.05$, vs. $\mathrm{Mg} 2 \mathrm{mM}, \mathrm{Mg} 2 \mathrm{mM}+\mathrm{Rv} 0.5 \mu \mathrm{M}$, and $\mathrm{Mg} 2 \mathrm{mM}+\mathrm{Rv} 0.5 \mu \mathrm{M}+\mathrm{Gm} 20 \mu \mathrm{M},{ }^{\dagger} \mathrm{P}<0.05, \mathrm{vs} . \mathrm{Mg} 1.5 \mathrm{mM}, \mathrm{Mg} 2 \mathrm{mM}$ + Rv $0.5 \mu \mathrm{M}$, and $\mathrm{Mg} 2 \mathrm{mM}+\operatorname{Rv} 0.5 \mu \mathrm{M}+\mathrm{Gm} 20 \mu \mathrm{M},{ }^{\S} \mathrm{P}<0.05$, vs. $\mathrm{Mg} 2 \mathrm{mM}+\mathrm{Rv} 0.5 \mu \mathrm{M}+\mathrm{Gm} 20 \mu \mathrm{M},{ }^{\prime \prime} \mathrm{P}<0.05$, vs. Mg $1.5 \mathrm{mM}+\mathrm{Rv} 0.5 \mu \mathrm{M}$, and ${ }^{9} \mathrm{P}<0.05$, vs. $\mathrm{Mg} 2 \mathrm{mM}+\mathrm{Rv} 0.5 \mu \mathrm{M}$ and $\mathrm{Mg} 2 \mathrm{mM}+\operatorname{Rv} 0.5 \mu \mathrm{M}+\mathrm{Gm} 20 \mu \mathrm{M}$ by t-test with Bonferroni's correction.

ST equal to or greater than baseline tensions at concentrations less than $5 \mu \mathrm{M}$ (Fig. 8).

\section{Discussion}

Magnesium, which possesses numerous beneficial physiologic properties, has been used widely in anesthetic practice.
Anesthesiologists often see patients with hypo- or hypermagnesemia perioperatively because many patients with pre-existing conditions such as diabetes mellitus, hyperaldosteronism, and eclampsia are vulnerable to magnesium treatment. Because these patients who visit operating rooms commonly take drugs such as diuretics, parathyroid hormone, and aminoglycosides [13], anesthesiologists should be aware of the actions, side effects, and 
A

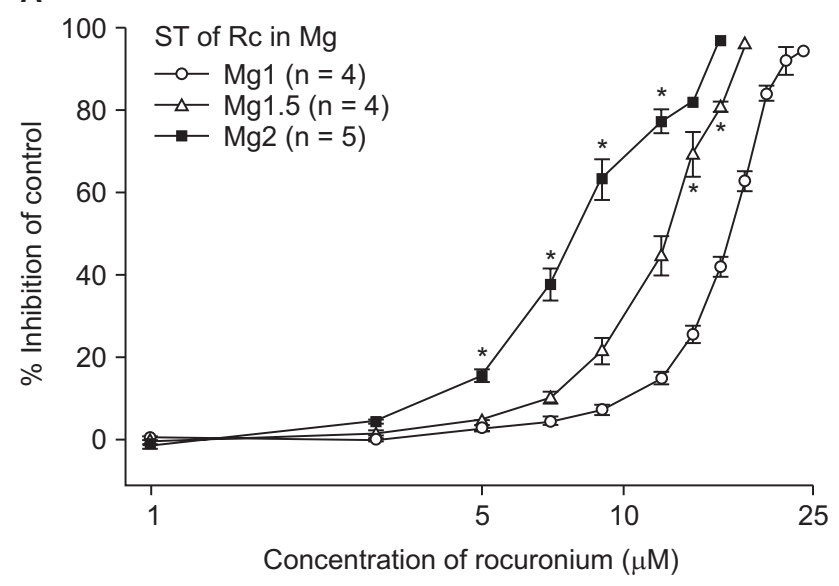

C

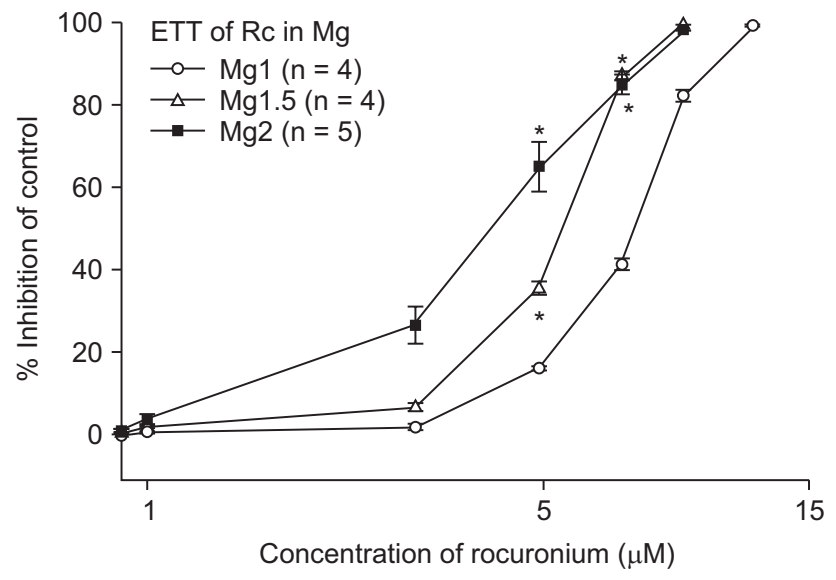

drug interactions of magnesium. Furthermore, the NM blockade by magnesium can be aggravated by co-administering with drugs such as ropivacaine, gentamicin, and rocuronium, which were investigated in this study and have different mechanisms on NM block.

An understanding of how ST and TT act on the NM junction, and what affects their depression, could help to identify the mechanisms of NM block. Therefore, this study examined ST and TT at progressively increasing drug concentrations. The stimulation of ST at motor nerve terminals releases acetylcholine (Ach) that subsequently binds to acetylcholine receptors (AchR) in the end-plate. Thus, drugs that cause ST depression may block at either presynaptic or postsynaptic locations $[14,15]$. Tetanic stimulation causes the synaptic release of Ach and the abundant release of Ach can act as positive feedback [16] on presynpatic AchR which causes an increase in intracellular calcium which ultimately enhances the synthesis of Ach [14,15]. Tetanic tension consists of two components, PTT and ETT. PTT can be measured $0.2 \mathrm{~s}$ after tetanic stimulation [14] to evaluate the readily releasable pool of Ach [17]. ETT can be assessed at the end of tetanic tension (1.9 s after tetanic stimulation) to measure

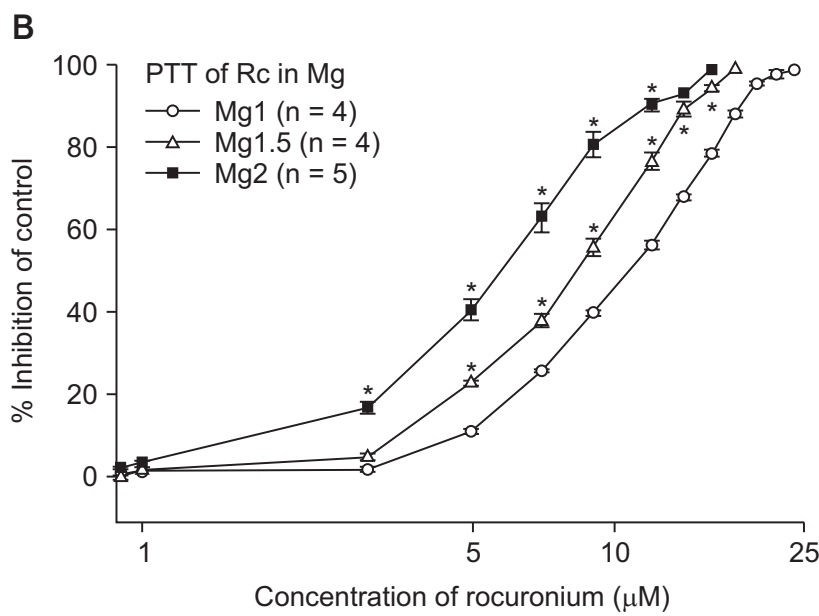

Fig. 7. Based on the cumulative concentration-response (C-R) curves of rocuronium on ST (A), PTT (B) and ETT (C), $\mathrm{MgCl}_{2}$ shifts the $\mathrm{C}-\mathrm{R}$ curves of rocuronium to the left; hence, it increases the potency of rocuronium. The concentration of rocuronium is transformed to $\log$ concentration. Data are presented as mean \pm SEM. The unit of concentrations for $\mathrm{Mg}$ is $\mathrm{mM}$. $\mathrm{n}$ is the number of experiments. $\mathrm{Mg}$ : magnesium chloride, Rc: rocuronium, ST: single twitch, PTT: peak tetanic tension, and ETT: end tetanic tension. ${ }^{*} \mathrm{P}<0.05$, vs. $\mathrm{Mg} 1 \mathrm{mM}$ by t-test with Bonferroni's correction.

Ach secretion as a result of the synthesis and mobilization of Ach [18]. The decrease in Ach synthesis and mobilization [16], the diminution of Ach content and number of qaunta [14], and the desensitization and blockage of available AchR [19] may lead to tetanic fade.

Because of the frequency of hypermagnesemia among patients in the operating room setting, the magnesium concentration used for pretreatment in this study was set above clinically relevant levels. Magnesium sulfate concentrations ranging from 1.8 to $3.1 \mathrm{mM}$ have been used for the treatment of eclamptic convulsion, but higher concentrations may cause dose-dependent fatal complications, such as respiratory hold and cardiac arrest [20]. The concentration of $\mathrm{MgCl}_{2}$ used in this study (1 to $4 \mathrm{mM}$ ) is within the therapeutic range, but as $\mathrm{MgCl}_{2}$ is more potent than $\mathrm{MgSO}_{4}$, the concentration used in this study reached higher than clinically relevant levels. For ropivacaine and gentamicin, clinically relevant concentrations were used to investigate the synergistic effect on NM inhibition. In an animal study by Arthur et al., the maximal concentration $\left(\mathrm{C}_{\max }\right)$ of ropivacaine was $2.4 \mu \mathrm{g} / \mathrm{ml}(\fallingdotseq 8.80 \mu \mathrm{M})$ after intravenous infusion of 3.0 $\mathrm{mg} / \mathrm{kg}$ [7]. In addition, after epidural administration of $3.0 \mathrm{ml}$ 
A

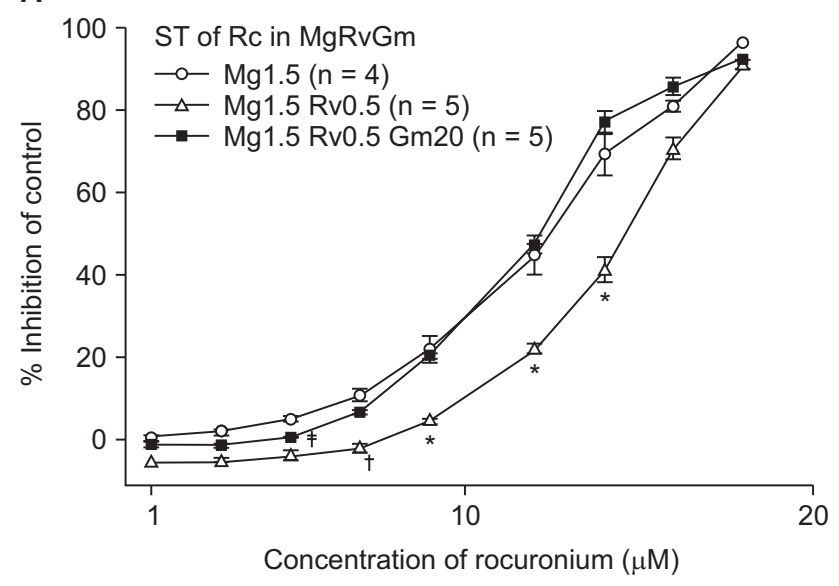

C

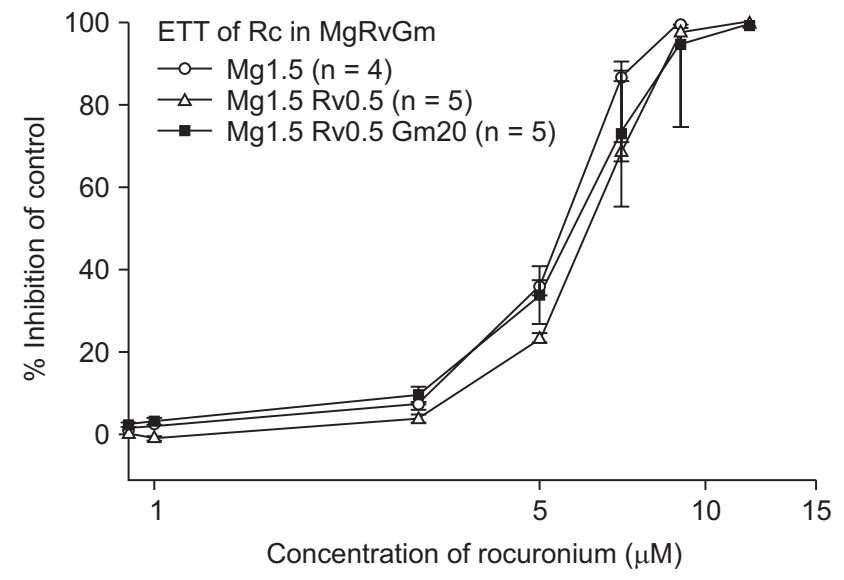

of $0.75 \%$ ropivacaine, the $\mathrm{C}_{\max }$ was $0.5 \mu \mathrm{g} / \mathrm{ml}(\fallingdotseq 1.82 \mu \mathrm{M})$ [7]. As the unbound form of ropivacaine is $6.1 \%$ [21], the maximum levels of free ropivacaine after intravenous and epidural administration are $0.54 \mu \mathrm{M}$ and $0.11 \mu \mathrm{M}$, respectively. Based on the study by Arthur et al., $0.5 \mu \mathrm{M}$ ropivacaine used in this study for pretreatment is within the expected therapeutic plasma concentration; levels above that concentration are regarded as clinically high. The therapeutic $\mathrm{C}_{\max }$ of gentamicin is $12 \mu \mathrm{g} / \mathrm{ml}(\fallingdotseq 21 \mu \mathrm{M})$ [22]. The non-specific protein binding of gentamicin is low and clinically insignificant; therefore, the levels of unbound gentamicin are reflective of the plasma concentration [23]. Thus, the 20 $\mu \mathrm{M}$ dose of gentamicin used in this study for the pretreatment is within the therapeutic plasma concentrations.

Magnesium sulfate is more routinely used for treatment than other magnesium salts such as $\mathrm{MgCl}_{2}$, magnesium aspartate, and magnesium citrate $[2,13]$. However, another study comparing $\mathrm{MgSO}_{4}$ and $\mathrm{MgCl}_{2}$ demonstrated that $\mathrm{MgSO}_{4}$ is not superior to $\mathrm{MgCl}_{2}$ in pharmacological and clinical properties; therefore, $\mathrm{MgCl}_{2}$ may be a suitable replacement for magnesium [2]. $\mathrm{MgCl}_{2}$ and $\mathrm{MgSO}_{4}$ have different anions and, therefore, may show differences in $\mathrm{NM}$ inhibition. For example, the $\mathrm{EC}_{50}$ of $\mathrm{MgCl}_{2}$ was

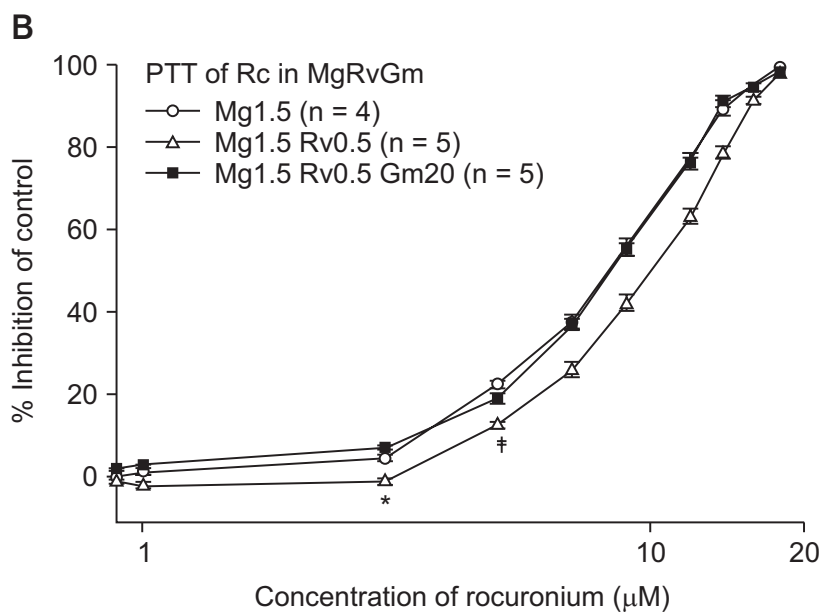

Fig. 8. Based on the cumulative concentration-response (C-R) curves of rocuronium on ST (A), PTT (B) and ETT (C), pretreated $0.5 \mu \mathrm{M}$ ropivacaine added to $1.5 \mathrm{mM} \mathrm{MgCl}_{2}$ shifts the $\mathrm{C}-\mathrm{R}$ curves of rocuronium to the right; hence it antagonizes the effect of rocuronium in $1.5 \mathrm{mM} \mathrm{MgCl}$. The concentration of rocuronium is transformed to $\log$ concentration. Data are presented as mean \pm SEM. The units of concentrations for $\mathrm{Mg}, \mathrm{Rv}$, and $\mathrm{Gm}$ are $\mathrm{mM}, \mu \mathrm{M}, \mu \mathrm{M}$, respectively. $\mathrm{n}$ is the number of experiments. Gm: gentamicin, Mg: magnesium chloride, Rc: rocuronium, Rv: ropivacaine, ST: single twitch, PTT: peak tetanic tension, ETT: end tetanic tension. ${ }^{*} \mathrm{P}<0.05$, vs. $\mathrm{Mg} 1.5 \mathrm{mM}+$ Rv $0.5 \mu \mathrm{M}+\mathrm{Gm} 20 \mu \mathrm{M},{ }^{\dagger} \mathrm{P}<0.05$, vs. Mg $1.5 \mathrm{mM}+\mathrm{Rv} 0.5 \mu \mathrm{M}+\mathrm{Gm}$ $20 \mu \mathrm{M}$ and $\mathrm{Mg} 1.5 \mathrm{mM}$, and ${ }^{\dagger} \mathrm{P}<0.05$, vs. $\mathrm{Mg} 1.5 \mathrm{mM}$ by t-test with Bonferroni's correction.

significantly lower than that of $\mathrm{MgSO}_{4}$. In addition, the ionized, biologically active form of $\mathrm{MgSO}_{4}$ may be less than that of $\mathrm{MgCl}_{2}$, thus leading to elevated potency of $\mathrm{MgCl}_{2}$ compared to $\mathrm{MgSO}_{4}$. Other comparative studies between $\mathrm{MgCl}_{2}$ and $\mathrm{MgSO}_{4}$ have reported increased efficacy of $\mathrm{MgCl}_{2}$ due to absorption, cellular penetration, and membrane effects [2]. $\mathrm{MgCl}_{2}$ was used for the current study with the goal of potentially increasing its future perioperative use.

The effects of magnesium on neuromuscular junctions are as follows: dose-dependent competition with calcium at presynaptic terminals and consequent inhibition of calcium-dependent acetylcholine release, which decreases the depolarizing action of Ach at the end plate and leads to the direct depression of muscle fiber membrane excitability [4]. In this study, higher concentrations of $\mathrm{MgCl}_{2}$ caused ST to disappear while PTT and ETT remained. This result can be explained by the most dominant mechanism of magnesium, which is the depression of presynaptic release of Ach. When tetanic stimulation is exerted, it increases the intracellular calcium ion concentration [14] and consequently antagonizes the presynaptic blocking action of magnesium [24]. In addition, Lee et al. [24] reported that mag- 
A

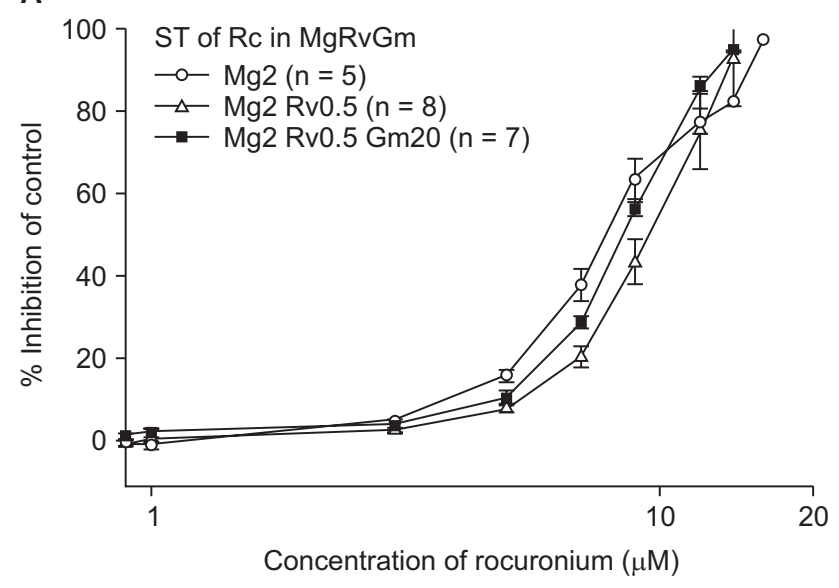

C

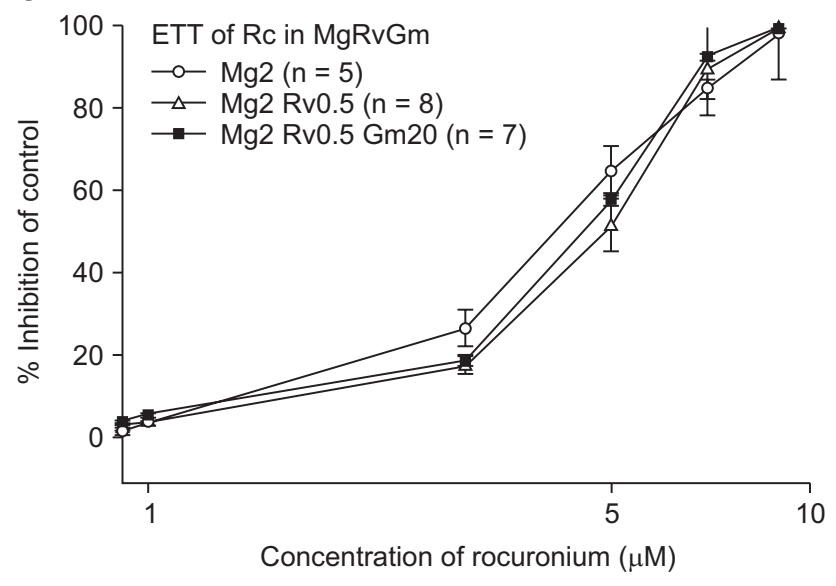

nesium produced tetanic ascent instead of tetanic fade whereby tetanic stimulation caused the accumulation of calcium in the nerve endings, leading to the enhancement of post-tetanic potentiation [24].

Ropivacaine belongs to the amino amide class of local anesthetics, which is structurally similar to but less toxic than bupivacaine [6,7]. Like other local anesthetics, it may act on the motor nerve terminal and also motor nerve conduction to interfere with NM transmission [8-10]. At the motor nerve terminal, it may reduce the mean open time of AchR, desensitize AchR, inhibit the synthesis of Ach, decrease Ach content or number of quanta released at rest or during nerve stimulation, diminish the mobilization of Ach, and inhibit the absorption of Ach to its receptors on the postsynaptic membrane $[8,9]$. It may also interfere with the open and inactivated states of sodium channels, thus blocking motor nerve conduction [10].

In this study, ETT and PTT of ropivacaine began to decrease at lower concentrations than ST did. The possible mechanisms include strong inhibition of presynaptic Ach synthesis or release. In addition, open ion channels at the presynaptic junction may be blocked to reduce the mean open time $[25,26]$. At lower con-

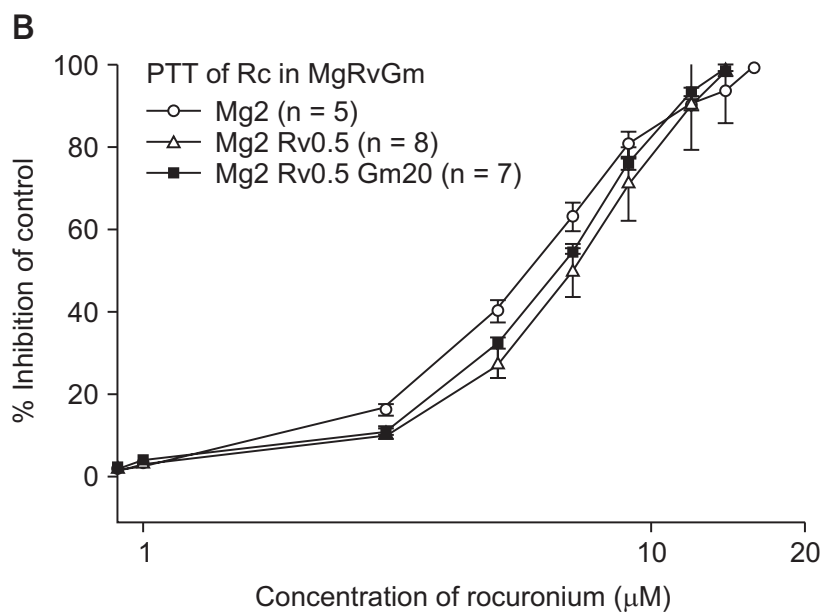

Fig. 9. Based on the cumulative concentration-response (C-R) curves of rocuronium on ST (A), PTT (B) and ETT (C), pretreated $0.5 \mu \mathrm{M}$ ropivacaine added to $2 \mathrm{mM} \mathrm{MgCl}_{2}$ shifts the $\mathrm{C}$ - $\mathrm{R}$ curves of rocuronium to the right; however, there is no statistical significance. The addition of $20 \mu \mathrm{M}$ gentamicin to rocuronium moved the C-R curves to the left; hence it reversed the antagonistic action of ropivacaine. Data are presented as mean \pm SEM. The units of concentrations for $\mathrm{Mg}$, Rv, and $\mathrm{Gm}$ are $\mathrm{mM}, \mu \mathrm{M}, \mu \mathrm{M}$, respectively. $\mathrm{n}$ is the number of experiments. $\mathrm{Gm}$ : gentamicin, Mg: magnesium chloride, Rc: rocuronium, Rv: ropivacaine, ST: single twitch, PTT: peak tetanic tension, ETT: end tetanic tension.

centrations of ropivacaine, the current study also showed that PTT and ETT, and especially ST, were above baseline. On the basis of this result, it seems likely that at lower concentrations, ropivacaine may intensify the postsynaptic AchR response and also increase Ach release, which then acts as a positive feedback loop on presynaptic AchR leading to an increase in intracellular calcium [9]. In addition, at higher concentrations of ropivacaine, NM block by hindering motor nerve conduction may be more dominant than its action at motor nerve terminal; therefore, the decline of ST, PTT, and ETT may be prominent.

Like magnesium, gentamicin blocks presynaptic voltagegated calcium channels and diminishes the release of Ach at the motor nerve terminal $[11,12,14]$. At higher concentrations of gentamicin, the increased intracellular calcium concentration elicited by tetanic stimulation may cause the existence of PTT and ETT. However, gentamicin is different from magnesium in that it produces tetanic fade [11]. Therefore, although the two drugs share a common mechanism of NM block, the process by which they antagonize calcium channels may be different.

Rocuronium induces muscle paralysis by competitively binding to postsynaptic nicotinic cholinergic receptors at the 
myoneural junction [27]. In this study, similar to ropivacaine, tetanic tension reduction appeared at lower concentrations of rocuronium than ST inhibition. However, the mechanisms by which rocuronium and ropivacaine cause tetanic tension inhibition at these lower concentrations are different. Ropivacaine inhibits AchRs and consequently decreases the synthesis of Ach, but rocuronium blocks AchR and thus inhibits the mobilization of Ach [9]. These observations may explain why the potency ratio of ST and TT reduction was greater for ropivacaine than for rocuronium.

Each of the four drugs used in this study showed different mechanisms of NM block, and so it was hypothesized that they interact synergistically to consequently intensify muscle paralysis. Consistent with this hypothesis, magnesium interacted synergistically with ropivacaine, gentamicin and rocuronium. However, when a low concentration of ropivacaine was added to pretreatment, the potency of gentamicin and rocuronium decreased.

As the pretreatment concentration of magnesium increased in this study, magnesium potentiated the effect of ropivacaineinduced NM block. However, this effect was not statistically significant. The decreased concentration of Ach at nerve terminals by magnesium and inactivated ion channel of nicotinic AchR by ropivacaine augmented NM blocking action. In addition, magnesium-induced depression of muscle fiber membrane excitability and decreased motor nerve conduction by ropivacaine may lead to a synergistic effect. However, as ropivacaine potentiated ST, PTT, and ETT at lower concentrations, the synergistic interaction between magnesium and ropivacaine may not be as strong as that of magnesium with other drugs.

This study demonstrated that magnesium potentiated gentamicin-induced NM block. L'Hommedieu et al. [28] reported that a term neonate with hypermagnesemia secondary to $\mathrm{MgSO}_{4}$ administration to the mother for preeclampsia developed a respiratory hold after administration of gentamicin. From the reports, it may be possible to demonstrate that magnesium and gentamicin synergistically interact. Although the two drugs apparently interfere with the same ion channel for their NM blocking actions, the synergistic effect was still observed. This may be the result of different actions on the same ion channel. For example, Lee et al. [11] speculated that magnesium produces tetanic ascent while gentamicin induces tetanic fade [24]. However, the process by which these differential effects on tetanic tension are generated has not been verified.

The interaction between magnesium and rocuronium has been examined in several studies and most have reported a synergistic interaction between the two drugs [5,27,29]. Kussman el al. [5] speculated that pretreatment of $\mathrm{MgSO}_{4}$, given as a bolus injection over $1 \mathrm{~min}$, prolonged the duration of rocuroniuminduced NM block but did not shorten the onset. Czarnetzki el al. [29] also demonstrated that $\mathrm{MgSO}_{4}$, given 15 min before anesthesia, prolonged the total recovery time by about $25 \%$ and reduced the onset time of rocuronium by approximately $35 \%$. The two reports showed a similar prolongation of duration of rocuronium but different onset time courses. Since the action of magnesium on the NM junction is concentration- and time-dependent, the method of magnesium administration may be the reason for the different onset times [29]. Our study did not measure the magnesium effect on the onset time of rocuronium, but it revealed the expected result on the duration of muscle paralysis; magnesium pretreatment potentiated rocuronium-induced NM inhibition. The slightly different actions of magnesium and rocuronium on NM junction may cause this synergistic interaction between the two drugs. The magnesium-induced decrease of Ach release at the presynaptic nerve terminals may enhance the postsynaptic action of rocuronium [27].

Ropivacaine $(0.5 \mu \mathrm{M})$ interacted antagonistically or non-synergistically with magnesium, gentamicin, and rocuronium on the NM block in this study. The combination of $2.0 \mathrm{mM} \mathrm{MgCl}_{2}$ and $0.5 \mu \mathrm{M}$ ropivacaine antagonized the potency of gentamicin for ST, PTT, and ETT. In addition, $0.5 \mu \mathrm{M}$ ropivacaine added to rocuronium in $1.5 \mathrm{mM}$ or $2.0 \mathrm{mM} \mathrm{MgCl}_{2}$ decreased the potency of rocuronium. Similar to our study, Lee et al. [14] reported that $0.1 \mu \mathrm{M}$ bupivacaine did not increase the potency of rocuronium but a higher concentration of bupivacaine $(1$ or $2 \mu \mathrm{M})$ did. Furthermore, at lower concentrations, ropivacaine alone increased PTT and ETT, and especially ST. Potentiated ST, PTT, and ETT may result from increased Ach release that acts through a positive feedback loop on to presynaptic AchR, which leads to an increase in intracellular calcium. In turn, the increased intracellular calcium may antagonize the NM blocking action of magnesium and gentamicin. Consequently, ropivacaine, at lower concentrations, may decrease the potency of the drugs on NM transmission. However, Wang et al. [30] demonstrated that lidocaine and procaine significantly potentiated the NM inhibition of NMBAs by enhancing nicotinic AchR. The differing results between these studies of local anesthetics need further evaluation.

In conclusion, the concomitant administration of a high concentration of magnesium and ropivacaine and a clinically relevant concentration of gentamicin, and rocuronium potentiated NM blockade, while a clinically relevant concentration of ropivacaine did not. These data suggest that clinicians should pay close attention to patients when these drugs administered simultaneously and monitor muscle paralysis carefully during anesthesia.

\section{Acknowledgments}

This study was supported by research funds from Dong-A University. 


\section{References}

1. James MF. Clinical use of magnesium infusions in anesthesia. Anesth Analg 1992; 74: 129-36.

2. Durlach J, Guiet-Bara A, Pagès N, Bac P, Bara M. Magnesium chloride or magnesium sulfate: a genuine question. Magnes Res 2005; 18: 18792.

3. Sadeh M. Action of magnesium sulfate in the treatment of preeclampsia-eclampsia. Stroke 1989; 20: 1273-5.

4. Del-Castillo J, Engbaek L. The nature of the neuromuscular block produced by magnesium. J Physiol 1954; 124: 370-84.

5. Kussman B, Shorten G, Uppington J, Comunale ME. Administration of magnesium sulphate before rocuronium: effects on speed of onset and duration of neuromuscular block. Br J Anaesth 1997; 79: 122-4.

6. Feldman HS, Covino BG. Comparative motor-blocking effects of bupivacaine and ropivacaine, a new amino amide local anesthetic, in the rat and dog. Anesth Analg 1988; 67: 1047-52.

7. Arthur GR, Feldman HS, Covino BG. Comparative pharmacokinetics of bupivacaine and ropivacaine, a new amide local anesthetic. Anesth Analg 1988; 67: 1053-8.

8. Matsuo S, Rao DB, Chaudry I, Foldes FF. Interaction of muscle relaxants and local anesthetics at the neuromuscular junction. Anesth Analg 1978; 57: 580-7.

9. Lee JH, Lee SI, Lee SC, Choi SR, Rhee WJ. At therapeutic concentration bupivacaine causes neuromuscular blockade and enhances rocuronium-induced blockade. Korean J Anesthesiol 2012; 62: 468-73.

10. Butterworth JF 4th, Strichartz GR. Molecular mechanisms of local anesthesia: a review. Anesthesiology 1990; 72: 711-34.

11. Lee JH, Lee SI, Chung CJ, Lee JH, Lee SC, Choi SR, et al. The synergistic effect of gentamicin and clindamycin on rocuronium-induced neuromuscular blockade. Korean J Anesthesiol 2013; 64: 143-51.

12. Parsons TD, Obaid AL, Salzberg BM. Aminoglycoside antibiotics block voltage-dependent calcium channels in intact vertebrate nerve terminals. J Gen Physiol 1992; 99: 491-504.

13. Herroeder S, Schönherr ME, De Hert SG, Hollmann MW. Magnesium-essentials for anesthesiologists. Anesthesiology 2011; 114: 971-93.

14. Lee SI, Lee JH, Park SY, Park JW. Do bupivacaine, clindamycin, and gentamicin at their clinical concentrations enhance rocuroniuminduced neuromuscular block? Korean J Anesthesiol 2013; 64: 346-52.

15. Martyn JA. Neuromuscular physiology and pharmacology. In: Miller's Anesthesia. 7th ed. Edited by Miller DR: Philadelphia, Churchill Livingstone Elsevier 2010, pp 344-53.

16. Bowman WC, Webb SN. Tetanic fade during partial transmission failure produced by non-depolarizing neuromuscular blocking drugs in the cat. Clin Exp Pharmacol Physiol 1976; 3: 545-55.

17. Elmqvist D, Quastel DM. A quantitative study of end-plate potentials in isolated human muscle. J Physiol 1965; 178: 505-29.

18. Viby-Mogensen J. Neuromuscular monitoring. In: Miller's Anesthesia. 7th ed. Edited by Miller DR: Philadelphia, Churchill Livingstone Elsevier 2010, pp 1516-7.

19. de Oliveria MJ, Oliveria AC. Mechanisms underlying the vecuronium-induced tetanic fade in the isolated rat muscle. Pharmacol Toxicol 1999; 85: 282-7.

20. Lu JF, Nightingale CH. Magnesium sulfate in eclampsia and pre-eclampsia: pharmacokinetic principles. Clin Pharmacokinet 2000; 38: 30514.

21. Knudsen K, Beckman Suurküla M, Blomberg S, Sjövall J, Edvardsson N. Central nervous and cardiovascular effects of i.v. infusions of ropivacaine, bupivacaine and placebo in volunteers. Br J Anaesth 1997; 78: 507-14.

22. Caputy AJ, Kim YI, Sanders DB. The neuromuscular blocking effects of therapeutic concentrations of various antibiotics on normal rat skeletal muscle: a quantitative comparison. J Pharmacol Exp Ther 1981; 217: 369-78.

23. Myers DR, DeFehr J, Bennet WM, Porter GA, Olsen GD. Gentamicin binding to serum and plasma proteins. Clin Pharmacol Ther 1978; 23: 356-60.

24. Lee C, Zhang X, Kwan WF. Electromyographic and mechanomyographic characteristics of neuromuscular block by magnesium sulphate in the pig. Br J Anaesth 1996; 76: 278-83.

25. Neher E, Steinbach JH. Local anaesthetics transiently block currents through single acetylcholine-receptor channels. J Physiol 1978; 277: $153-76$.

26. Arias HR, Blanton MP. Molecular and physicochemical aspects of local anesthetics acting on nicotinic acetylcholine receptor-containing membranes. Mini Rev Med Chem 2002; 2: 385-410.

27. Pinard AM, Donati F, Martineau R, Denault AY, Taillefer J, Carrier M. Magnesium potentiates neuromuscular blockade with cisatracurium during cardiac surgery. Can J Anaesth 2003; 50: 172-8.

28. L'Hommedieu CS, Huber PA, Rasch DK. Potentiation of magnesium-induced neuromuscular weakness by gentamicin. Crit Care Med 1983; 11: $55-6$.

29. Czarnetzki C, Lysakowski C, Elia N, Tramèr MR. Time course of rocuronium-induced neuromuscular block after pre-treatment with magnesium sulphate: a randomised study. Acta Anaesthesiol Scand 2010; 54: 299-306.

30. Wang H, Zhang Y, Li ST. The effect of local anesthetics on the inhibition of adult muscle-type nicotinic acetylcholine receptors by nondepolarizing muscle relaxants. Eur J Pharmacol 2010; 630: 29-33. 